\title{
Solvent Extraction of Lanthanoid and Yttrium Ions with Poly(oxyethylene)alkylphenylether
}

\author{
Isao YoshidA*, Ryo'ichi Takeshita*, Keihei Ueno* and Makoto TAKagI** \\ *Department of Industrial Chemistry, Kumamoto Institute of Technology, Kumamoto 860 \\ **Department of Organic Synthesis, Faculty of Engineering, Kyushu University, \\ Hakozaki, Fukuoka 812
}

\begin{abstract}
Solvent extraction of lanthanoid and yttrium ions $\left(\mathrm{M}^{3+}\right)$ was investigated in a water-dichloroethane system using poly(oxyethylene)-type nonionic surfactants such as Triton $X-100$ and Triton $X-405(L)$ and picrate ion $\left(A^{-}\right)$as extraction agent and pairing anion, respectively. The result of extraction studies at various extraction agent concentrations and at various picrate ion concentrations, suggested that the composition of the extracted species was $\mathrm{MLA}_{3}$. Among the lanthanoid ions investigated, the ions such as $\mathrm{Nd}^{3+}, \mathrm{Sm}^{3+}, \mathrm{Eu}^{3+}$, and $\mathrm{Gd}^{3+}$ gave relatively larger distribution ratios than the other lanthanoid ions, while the yttrium ion was the least extractable among the metal ions investigated. The distribution ratio with extraction agent Triton $\mathrm{X}-405$ was about ten times larger than those with Triton X-100.
\end{abstract}

Keywords Solvent extraction, lanthanoid, Triton X, poly(oxyethylene)alkylphenylether

Nonionic surfactants containing polyethyleneglycol chain can extract some alkali and alkaline earth metal ions into organic solvents. However, very few extractions of other metal ions have been reported. Recently, polyethyleneglycols and their alkylphenylether derivatives were used to extract heavy metal ions such as cobalt and zinc, or actinoid ions such as uranium(VI), in the presence of large amounts of alkali, alkaline earth or ammonium thiocyanates. ${ }^{1-3}$ In this extraction system, the metal ion was extracted in the form of metal-thiocyanate anion complex, which was accompanied by a polyethyleneglycol complex of alkali, alkaline earth or ammonium ion as pairing cation.

In the present work, lanthanoid and yttrium ions are extracted with polyethyleneglycol alkylphenyl ether such as Triton $\mathrm{X}-100$ or Triton $\mathrm{X}-405$ into 1,2dichloroethane in the presence of picrate ion. The composition of extracted species and the relative ease of extraction of individual lanthanoids and yttrium ions are given for Triton $\mathrm{X}-100$ and Triton $\mathrm{X}-405$.

\section{Experimental}

\section{Reagents and apparatus}

Triton X-100 (decaethyleneglycol mono 4-(1,1,3,3tetramethylbutyl)phenyl ether), and Triton X-405 (tetracontaethyleneglycol mono 4-(1,1,3,3-tetramethylbutyl)phenyl ether) were commercial products and were used without further purification. Other reagents, including picric acid and 1,2-dichloroethane, were of analytical grade (Wako Pure Chem. Ind.). Lanthanoid and yttrium ions were used as chlorides except for thulium and lutetium ions. The oxides of the latter two ions were dissolved with hydrochloric acid, the excess of acid was evaporated and the solution was diluted with water.

Stock solutions of metal ion, picric acid and Triton $\mathrm{X}$ were standardized by EDTA titration, alkalimetry and gravimetry, respectively.

Absorbances were determined using Shimadzu UV180 spectrophotometer with standard $1 \mathrm{~cm}$ cells.

\section{Distribution ratio of metal ion}

Appropriate amounts of lanthanoid metal ion solution $\left((6.4-7.2) \times 10^{-4} \mathrm{M}, 1 \mathrm{M}=1 \mathrm{~mol} \mathrm{dm}^{-3}\right)$, picric acid solution and Triton $X$ solution were mixed and diluted to $10-15 \mathrm{ml}$ in a stoppered $50 \mathrm{~cm}^{3}$ glass tube. The same volume of 1,2-dichloroethane was then added to the mixture. The tube was shaken for $30 \mathrm{~min}$ at $35^{\circ} \mathrm{C}\left( \pm 2^{\circ} \mathrm{C}\right)$, and then centrifuged at 3000 r.p.m. for 5 min. No pH-buffer was used to avoid complexation with trivalent metals, but the $\mathrm{pH}$ of aqueous phase was generally in the range from 2.0 to 2.1 after all extractions.

The metal ion concentrations in the aqueous phase were determined for a $2 \mathrm{~cm}^{3}$ aliquot by absorption photometry using Xylenol Orange-hexadecylpridinium bromide(CPB) method $^{4}$ at $610 \mathrm{~nm}$ after diluting to 5 $\mathrm{cm}^{3}$. The metal ion concentrations in the organic phase were determined for a $5 \mathrm{~cm}^{3}$ aliquot according to the 
following procedure. The aliquot of organic phase was shaken with $10 \mathrm{~cm}^{3}$ of $1 \mathrm{M} \mathrm{HCl}$ at room temperature for $20 \mathrm{~min}$ to back-extract the metal ion. The $2 \mathrm{~cm}^{3}$ aliquot of the aqueous phase was then neutralized with $2 \mathrm{~cm}^{3}$ of $1 \mathrm{M} \mathrm{NaOH}$, and the metal concentration was determined by Xylenol Orange-CPB photometry. The metal ion concentrations other than those of lanthanoid and yttrium ions, were determined by atomic absorption photometry.

Distribution coefficients of Triton $X-100$ and $X-405$, and picric acid between 1,2-dichloroethane and water

Equal volumes of pure 1,2-dichloroethane and the aqueous solution containing Triton $\mathrm{X}$ or picric acid were taken and equilibrated by shaking for $30 \mathrm{~min}$ at $35^{\circ} \mathrm{C}\left( \pm 2^{\circ} \mathrm{C}\right)$. The initial concentrations of Triton $\mathrm{X}$ and picric acid ranged from 0.053 to $0.0126 \mathrm{M}$, and from 0.0424 to $0.00565 \mathrm{M}$, respectively. After equilibration, the concentrations of Triton $X$ in the both phases were determined by gravimetry for each 10 to $15 \mathrm{~cm}^{3}$ aliquot after evaporating the solvents. The concentrations of picric acid were determined by gravimetry on the organic phase after evaporating the solvent, and by alkalimetry on the aqueous phase. The $\mathrm{pH}$ of the aqueous phase was also measured to calculate the distribution coefficient of picric acid.

The distribution coefficients $\left(K_{\mathrm{d}, \mathrm{L}}=[\mathrm{L}]_{\mathrm{org}} /[\mathrm{L}]_{\mathrm{aq}}\right)$ determined were 24 for Triton $X-100$ and 30 for Triton X405. The value for picric acid (Kd, $\left.K_{\mathrm{dA}}=[\mathrm{HA}]_{\mathrm{org}} /[\mathrm{HA}]_{\mathrm{aq}}\right)$ was 96. The subscripts org and aq indicate the organic and aqueous phases, respectively.

The acid dissociation constant of picric acid in aqueous solution was determined spectrophotometrically to be $K_{\mathrm{a}, \mathrm{HA}}=0.480$ at $35^{\circ} \mathrm{C}$.

\section{Calculation}

First, one assumes that the solvent extraction of metal ion in this system can be expressed by the following equation:

$$
\mathbf{M}^{3+}+n \mathbf{L}+3 \mathbf{A}^{-}=\mathrm{ML}_{n} \mathbf{A}_{3}
$$

where $\mathrm{L}$ and $\mathrm{A}^{-}$are Triton $\mathrm{X}$ and picrate ion, respectively, and $\mathrm{M}^{3+}$ represents lanthanoid metal ion. Then, the distribution ratio, $D$, of metal ions can be given as

$$
D=\frac{\Sigma\left[\mathbf{M}^{3+}\right]_{\text {org }}}{\Sigma\left[\mathbf{M}^{3+}\right]_{\mathrm{aq}}}=\frac{\left[\mathrm{ML}_{n} \mathbf{A}_{3}\right]_{\mathrm{org}}}{\left[\mathrm{M}^{3+}\right]_{\mathrm{aq}}+\left[\mathrm{ML}_{n}{ }^{3+}\right]_{\mathrm{aq}}}
$$

However, under experimental conditions where a large excess of picrate ion is added, the concentration $\left[\mathrm{ML}_{n}{ }^{3+}\right]_{\mathrm{aq}}$ can be neglected in comparison with $\left[\mathrm{M}^{3+}\right]_{\mathrm{aq}}$, because $\left[\mathrm{ML}_{n}{ }^{3+}\right]_{\mathrm{aq}}$, once formed, is readily extracted into organic phase to form an ion pair with $A^{-}$. Accordingly, equation (2) can be simplified:

$$
D=\left[\mathrm{ML}_{n} \mathrm{~A}_{3}\right]_{\text {org }} /\left[\mathrm{M}^{3+}\right]_{\text {aq }}
$$

Now, the distribution coefficient, $K_{\mathrm{d}, \mathrm{L}}$, of Triton $\mathrm{X}$, the complex formation constant, $K_{\mathrm{f}}$, of metal-Triton $\mathrm{X}$ complex in aqueous phase, and the extraction constant, $K_{\text {ex }}$, of the ion pair can be defined in a conventional way, as summarized below.

$$
\begin{aligned}
& \mathrm{L}_{\mathrm{aq}} \rightleftarrows \mathrm{L}_{\mathrm{org}} ; K_{\mathrm{d}, \mathrm{L}}=[\mathrm{L}]_{\mathrm{org}} /[\mathrm{L}]_{\mathrm{aq}} \\
& \mathrm{M}^{3+}+n \mathrm{~L}_{\mathrm{aq}} \rightleftarrows \mathrm{ML}_{n}{ }^{3+}{ }_{\mathrm{aq}} \text {; } \\
& K_{\mathbf{f}}=\left[\mathrm{ML}_{n}^{3+}\right]_{\mathrm{aq}} /\left(\left[\mathrm{M}^{3+}\right][\mathrm{L}]^{n_{\mathrm{aq}}}\right) \\
& \mathrm{ML}_{n}{ }^{3+} \text { aq }+3 \mathrm{~A}^{-} \text {aq } \rightleftarrows \mathrm{ML}_{n} \mathrm{~A}_{3} \text { org; } \\
& K_{\text {ex }}=\left[\mathrm{ML}_{n} \mathrm{~A}_{3}\right]_{\text {org }} /\left[\mathrm{ML}^{3+}\right]_{\mathrm{aq}}\left[\mathrm{A}^{-}\right]^{3} \mathrm{aq}
\end{aligned}
$$

By combining equations (3) $-(6)$, equation (7) or (8) can be obtained.

$$
\begin{aligned}
& D=K_{\mathrm{ex}} K_{\mathrm{f}} K_{\mathrm{d}, \mathrm{L}^{-n}[\mathrm{~L}]_{\mathrm{org}}^{n}\left[\mathrm{~A}^{-}\right]^{3} \ldots \ldots \ldots \ldots \ldots \ldots \ldots \ldots \ldots \ldots \ldots \ldots} \\
& \log D=\log K_{\mathrm{ex}} K_{\mathrm{f}} K_{\mathrm{d}, \mathrm{L}}{ }^{-n}+n \log [\mathrm{L}]_{\mathrm{org}}+3 \log \left[\mathrm{A}^{-}\right]
\end{aligned}
$$

\section{Results and Discussion}

The results of our extraction study for lanthanum ion with Triton $\mathrm{X}-405$ and for dysprosium ion with Triton X-100 under constant picrate concentration and $\mathrm{pH}$, but under various Triton $X$ concentrations, are shown in Fig. 1. In these plots, the concentrations of Triton $\mathrm{X}$ in the organic phase were calculated by equation (9):

$$
[\mathrm{L}]_{\text {org }}=K_{\mathrm{d}, \mathrm{L}} T_{\mathrm{L}} /\left(V_{\mathrm{a}}+K_{\mathrm{d}, \mathrm{L}} V_{\mathrm{o}}\right)
$$

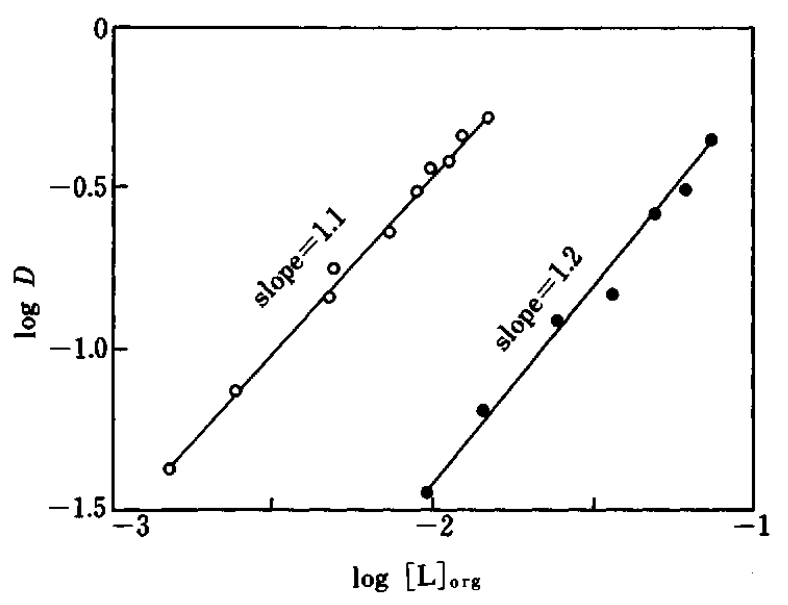

Fig. 1 Extraction of $\mathrm{La}^{3+}$ and $\mathrm{Dy}^{3+}$ into 1,2-dichloroethane with Triton $X$ and pricrate. Effect of Triton $X$ concentration on $\log D$. O, La-Triton X-405; , Dy-Triton X-100. Aqueous phase: $[\mathrm{HA}]_{\mathrm{T}}=0.0339 \mathrm{M}$; $[$ Metal $] \mathrm{T}=1 \times 10^{-4} \mathrm{M}$; $\mathrm{pH}=2.1$ (after equilibration). 


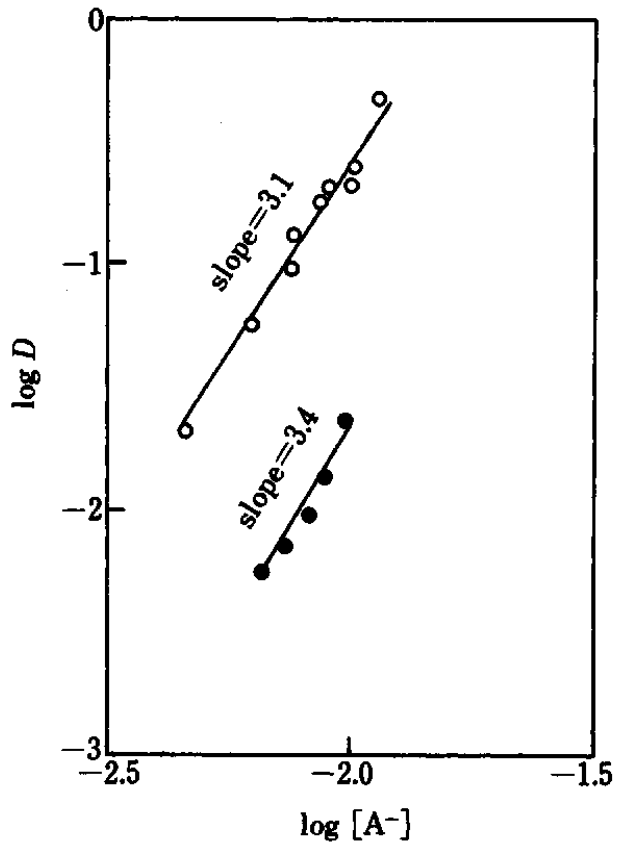

Fig. 2 Extraction of $\mathrm{La}^{3+}$ and $\mathrm{Dy}^{3+}$ into 1,2-dichloroethane with Triton $X$ and picrate. Effect of picrate ion concentration on $\log D . O$, La-Triton X-405-Aqueous phase: $[\mathrm{La}] \mathrm{T}=3.6 \times 10^{-4} \mathrm{M}, \mathrm{pH}=2.1-2.7$ (after equilibration); organic phase: $[\mathrm{L}] \mathrm{T}=0.0148 \mathrm{M}$. $\odot$, Dy-Triton $\mathrm{X}-100-$ -Aqueous phase: $[D y] \mathrm{T}=2.1 \times 10^{-4} \mathrm{M}, \mathrm{pH}=2.3-2.5$ (after equilibration); organic phase: $[\mathrm{L}] \mathrm{T}=0.0165 \mathrm{M}$.

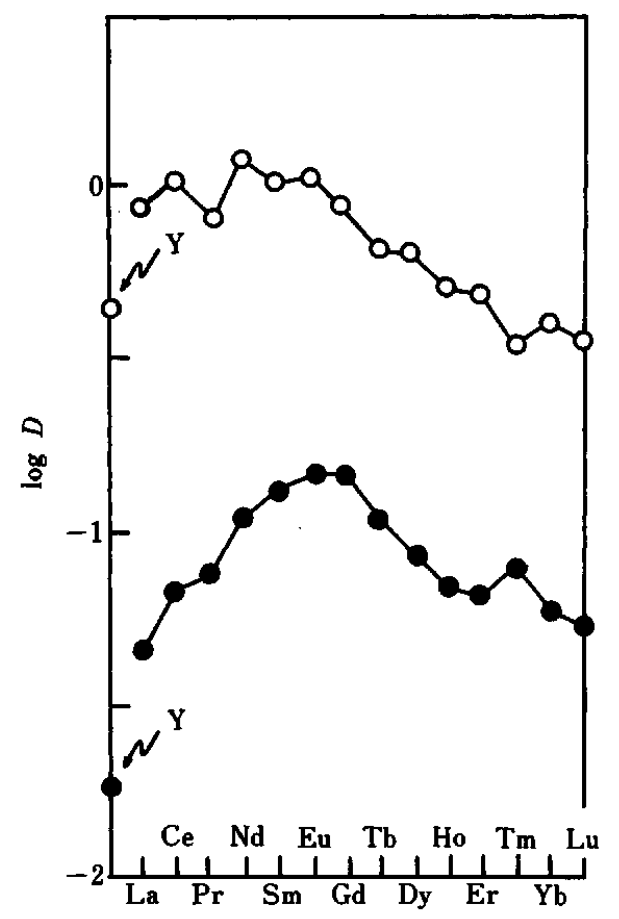

Fig. 3 Extraction of lanthanoid and yttrium ions into 1,2dichloroethane with Triton $X$ and picrate. $O$, Triton $X-$ 405; - Triton X-100. Aqueous phase: $[\mathrm{HA}] \mathrm{r}=0.0339 \mathrm{M}$, $\left[\right.$ Metal] $\mathrm{T}=1 \times 10^{-4} \mathrm{M}, \mathrm{pH}=\mathbf{2 . 1}$ (after equilibration); organic

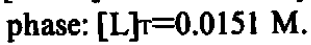

where $T_{\mathrm{L}}, V_{\mathrm{a}}$ and $V_{\mathrm{o}}$ are the total amount $(\mathrm{mol})$ of Triton $\mathrm{X}$ used in the extraction, the volume of aqueous phase and the volume of organic phase, respectively. The linear relationship of these plots indicates the validity of equation (8). The mole ratio of Triton $X$ to metal ion in the complex can be evaluated from the slope of linear plots, the ratio being $1: 1$ for both Triton $X-100$ and $X-405$ within experimental error.

The results of similar extraction studies for constant Triton $\mathrm{X}$ concentration, but various picrate concentrations and $\mathrm{pH}$, are shown in Fig. 2. In these plots, the concentrations of picrate ion in the aqueous phase were calculated by the following equation,

$$
\left[\mathrm{A}^{-}\right]=K_{\mathrm{a}, \mathrm{HA}} T_{\mathrm{HA}} /\left\{\left[\mathrm{H}^{+}\right]\left(1+V_{\mathrm{o}} V_{\mathrm{a}}^{-1} K_{\mathrm{a}, \mathrm{HA}}\right)+K_{\mathrm{a}, \mathrm{HA}}\right\}
$$

where $T_{\mathrm{HA}}$ is the total amount of picric acid used. The slope of linear plots is about 3, indicating that the composition of extracted complex is in fact $\mathrm{MLA}_{3}$ as assumed before.

The results of extraction study for individual lanthanoid ions and yttrium ion with Triton $X-100$ and Triton $X-405$ at constant Triton $X$ and picrate concentrations are summarized in Fig. 3, where $\log D$ values are plotted according to the increasing atomic number of the elements. The $\mathrm{pH}$ of aqueous phase after equilibration was between 2.0 and 2.1.

It is seen from this figure that the early middle members of lanthanoid ions, such as $\mathrm{Nd}^{3+}, \mathrm{Sm}^{3+}, \mathrm{Eu}^{3+}$ and $\mathrm{Gd}^{3+}$ can be extracted more easily than the rest of lanthanoid ions, regardless of the nature of extractants, i.e., Triton $X-405$ and $X-100$. In a similar experiment on the extraction of lanthanoid ions with nitrobenzene solution of crown ether in the presence of picrate, $\mathrm{Tb}^{3+}$ was the most easily extracted. This result was explained by the hole-size fitting theory between crown ether and metal ion, although the explanation based solely on the size effect is not so straightforward. ${ }^{5}$

In the present study, where an open chain polyether

Table $1 \log D$ values of some divalent metal ions in the extraction with Triton $\mathrm{X}-405$ and picrate. 1,2-dichloroethane-water ${ }^{2}$

\begin{tabular}{cc}
\hline Metal ion, $\mathrm{M}^{2+}$ & $\log D$ \\
\hline $\mathrm{Ca}$ & -1.29 \\
$\mathrm{Mg}$ & -1.64 \\
$\mathrm{Cu}$ & -1.13 \\
$\mathrm{Ni}$ & -1.62 \\
$\mathrm{Co}$ & $<-3.0$ \\
$\mathrm{Fe}$ & -1.77
\end{tabular}

a. Aqueous phase: $[\mathrm{HA}]_{\mathrm{T}}=0.0339 \mathrm{M},[\text { Metal }]_{\mathrm{T}}=(12.5-4.72) \times$ $10^{-4} \mathrm{M}$; organic phase: $[\mathrm{L}] \mathrm{T}=0.0151 \mathrm{M} ; \mathrm{pH}=2.1$ (after equilibration) 
is used, such a size effect can not be expected, and the interaction between ether oxygen and metal ion may be weak and in effective conpetition with that between hydration water oxygen and metal ion. Although the actual reason is not understood, the upward convex curves of $\log D$ against the atomic number shown in Fig. 3 can be attributed to such a competition of water and polyether.

The distribution coefficient of the complexes with Triton X-405 is higher than that of those with Triton $\mathrm{X}-100$; this may be due to the higher distribution ratio of Triton X-405 in water-dichloroethane systems.

Table 1 summarizes the result of extraction studies on some divalent metal cations under the conditions given in Fig. 3. It is seen from this table that the $\log D$ values of these cations are lower than those of lanthanoid and yttrium ions, showing that divalent metal ions behave quite differently from lanthanoid ions in this extraction system.

\section{References}

1. T. Sotobayashi, T. Suzuki and S. Tonouchi, Chem. Lett., 1976, 585.

2. T. Sotobayashi, T. Suzuki and K. Yamada, Chem. Lett., 1976, 77.

3. T. Sotobayashi, T. Suzuki and H. Kudo, J. Radioanal. Chem., 36, 145 (1977).

4. M. Otomo and Y. Wakamatsu, Bunseki Kagaku, 17, 764 (1968).

5. L. M. Tsay, J. S. Shih and S. C. Wu, Analyst [London], 108, 1108 (1983).

(Received October 16, 1985) (Accepted November 29, 1985) 